\title{
"Price and market risk reduction for bond portfolio selection in BRICS markets"
}

\begin{tabular}{|c|c|}
\hline AUTHORS & $\begin{array}{l}\text { Sergio Ortobelli Lozza (D) https://orcid.org/0000-0003-4983-8165 } \\
\text { Filomena Petronio } \\
\text { Sebastiano Vitali (D https://orcid.org/0000-0002-6984-4194 }\end{array}$ \\
\hline ARTICLE INFO & $\begin{array}{l}\text { Sergio Ortobelli Lozza, Filomena Petronio and Sebastiano Vitali (2018). Price } \\
\text { and market risk reduction for bond portfolio selection in BRICS markets. } \\
\text { Investment Management and Financial Innovations, 15(1), 120-131. } \\
\text { doi:10.21511/imfi.15(1).2018.11 }\end{array}$ \\
\hline DOI & http://dx.doi.org/10.21511/imfi.15(1).2018.11 \\
\hline RELEASED ON & Tuesday, 20 February 2018 \\
\hline RECEIVED ON & Monday, 09 October 2017 \\
\hline ACCEPTED ON & Monday, 12 February 2018 \\
\hline LICENSE & $\begin{array}{l}(c) \mathrm{EY}_{\mathrm{EY}} \\
\text { This work is licensed under a Creative Commons Attribution } 4.0 \text { International } \\
\text { License }\end{array}$ \\
\hline JOURNAL & "Investment Management and Financial Innovations" \\
\hline ISSN PRINT & $1810-4967$ \\
\hline ISSN ONLINE & $1812-9358$ \\
\hline PUBLISHER & LLC "Consulting Publishing Company "Business Perspectives" \\
\hline FOUNDER & LLC "Consulting Publishing Company "Business Perspectives" \\
\hline
\end{tabular}

NUMBER OF REFERENCES

29

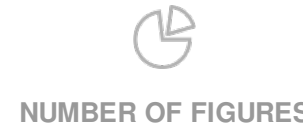

10
NUMBER OF TABLES

1

(C) The author(s) 2022. This publication is an open access article. 


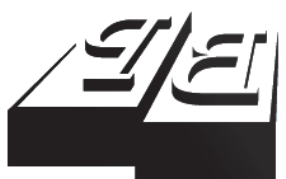

BUSINESS PERSPECTIVES

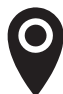

LLC "CPC "Business Perspectives" Hryhorii Skovoroda lane, 10, Sumy, 40022, Ukraine

www.businessperspectives.org

Received on: $9^{\text {th }}$ of October, 2017 Accepted on: $12^{\text {th }}$ of February, 2018

(C) Sergio Ortobelli Lozza, Filomena Petronio, Sebastiano Vitali, 2018

Sergio Ortobelli Lozza, Ph.D., Department of Management, Economics and Quantitative Methods, University of Bergamo, Italy.

Filomena Petronio, Ph.D., Department of Management, Economics and Quantitative Methods, University of Bergamo, Italy.

Sebastiano Vitali, Ph.D., Department of Probability and Mathematical Statistics, Faculty of Mathematics and Physics, Charles University, Prague, Czech Republic.

\section{(c) (i)}

This is an Open Access article, distributed under the terms of the Creative Commons Attribution 4.0 International license, which permits unrestricted re-use, distribution, and reproduction in any medium, provided the original work is properly cited.
Sergio Ortobelli Lozza (Italy), Filomena Petronio (Italy),

Sebastiano Vitali (Czech Republic)

\section{PRICE AND MARKET RISK REDUCTION FOR BOND PORTFOLIO SELECTION IN BRICS MARKETS}

\begin{abstract}
This paper focuses on classical portfolio strategies applied to five countries, which are Brazil, Russia, India, China and South Africa. These five countries form the so-called BRICS group. In particular, the authors investigate their corporate and sovereign bond market and evaluate whether these markets can represent a profitable investment for non-satiable and risk-averse investors. Two-step optimization is proposed to control price risk and market risk. For price risk management, classical immunization strategies and are obtained funds of bond are obtained that share the same risk measure. For market risk control, the previously found funds are used and a performance measure optimization commonly used in stock markets is applied to define the best portfolio of funds. Therefore, the resulting optimal portfolio controls the price risk and jointly maximizes a desired performance measure that includes the market risk. Finally, the authors propose an empirical analysis to evaluate the profitability of the suggested twostep optimization for the five BRICS countries and compare the ex-post sample paths of the obtained portfolios for testing the stochastic dominance relations.
\end{abstract}

\section{Keywords}

portfolio optimization, portfolio selection, emerging markets, bond portfolio, immunization theory, stochastic dominance

JEL Classification

G11

\section{INTRODUCTION}

A well-known set of developing countries is grouped as the emerging markets economies (EMEs). A subset of these emerging countries is identified in O'Neill (2011) and includes Brazil, Russia, India and China and thus it is named BRIC. Afterwards, to include South Africa, the acronym became BRICS (with a capital S). In our analysis, we consider the latter extended group and we extend the preliminary work made in Petronio et al. (2014) and Ortobelli and Petronio (2015). In particular, Petronio et al. (2014) investigate stock portfolio selection in BRICS markets assuming a Markov model for portfolio return; Ortobelli and Petronio (2015) consider BRICS fixed income markets, but do not propose an extended empirical comparison between the results obtained in each country. In this paper, we deeply evaluate and compare portfolio selection in fixed income BRICS market completing and finalizing the analysis made in Ortobelli and Petronio (2015). In recent years, both during the pre-crisis (before 2007) and during the economic crisis, the BRICS markets achieved much better performance than European and US markets. The physiological slowdown in the crisis period occurred because of the reduction of the demand from BRICS' trading partners in Europe and North America. However, 
it was a less dramatic decline than that in Europe and in the United States. In fact, even during the global financial crisis, the default rate in developing countries has always been relatively low. Moreover, the BRICS GDP (in nominal terms) grew despite their economic dimensions remaining small. This evidence is dependent on the recent appreciation of their currencies and on their growth rate which remained positive, while the advanced countries growth rates were far below their average (see the International Monetary Fund report) (IMF, 2011). The strong economic growth observed in BRICs markets during the recent years and their uncorrelated behavior with respect to the developed economies have created many investment opportunities. Moreover, market globalization and deregulation have made the BRICS highly attractive for investors. These markets have many common characteristics and represent a good opportunity of diversification for many investors, both local and foreign. Some problems persist, for instance, the significant lack of investors who constantly invest in these markets. Indeed, most agents who operate in these markets are so-called crossover investors. This behavior determines an 'on-off' access resulting in huge asset prices volatility (Mathieson \& Schinasi, 2001). Another issue of these markets is the so-called shortage assets phenomenon, i.e. the lack of securities issuance (in both equity and bond markets) that determines some distortion effects, such as the so-called buy-and-hold investment strategy that makes these markets illiquid (De la Torre \& Schmukler, 2006; Thompson, 2010). Despite such problems, the number of foreign investors operating in the BRICS markets is increasing. However, in both cases, local and foreign institutional investors are more frequent than retail and their operations are mainly limited to traditional investment and do not include innovative financial products (Thompson, 2010).

In this paper, we want to investigate the bond markets of BRICS and to evaluate their portfolio performance comparing the ex-post wealth obtained with a double step optimization. While dealing with developed country bonds is relatively easy and has been analyzed extensively in literature (Bertocchi et al., 2013), the focus on the bond market is particularly challenging when considering BRICS countries because the value of a bond is strictly linked to the creditworthiness of the issuer. For this reason, portfolio models are usually applied to credit risk clusters. Bertocchi et al. (2005) suggested a methodology to analyze multiple credit rating buckets simultaneously and to capture the change in yields and spread. Moreover, several models have addressed default risk. Cassader et al. (2014) managed default risk in bond portfolio selection problems by introducing credit default swap (CDS) contracts, Fooladi et al. (1997) proposed a general expression for duration in the presence of default risk. Zenios (1995) proposed an extensive analysis using three models sensitive to changes in the interest rates, managing portfolios of mortgage-backed securities which provide a general framework for fixed-income portfolios under uncertainty.

For our analysis, we consider time series of bonds prices in the BRICS markets using data from the provider Thomson Reuters DataStream starting from 2012 to perform a two-phase analysis. Thus, first, using the classical immunization theory and considering a set of fixed duration values, we create a set of immunized funds. The immunization theory has been studied extensively (see e.g. Redington, 1952; Weil, 1973; Vašiček, 1977; Paroush \& Prisman, 1997; Balbàs et al., 2002; Munk, 2011; Ortobelli et al., 2016). We adopt the approach introduced by Fisher and Weil (1971). Second, considering the set of immunized funds as assets, we create optimal portfolios maximizing the Sharpe ratio, and then, using a rolling horizon strategy, we determine the performance we would have obtained if we had invested in these markets over the last decade.

The paper is organized as follows. In section 1, we describe the portfolio selection problem. In section 2, we propose the ex-post empirical analysis applied to the BRICS bond markets. In particular, section 2.1 contains the results of the first phase, section 2.2 presents the results of the second phase and section 2.3 describes the test for stochastic dominance relations. Conclusions are outlined in final section. 


\section{PORTFOLIO SELECTION MODEL}

The portfolio selection problem is traditionally studied in terms of reward and risk. The concept of reward and risk is not unique and depends on the considered security. When we deal with the portfolio problem with plain vanilla bonds, the measure of reward is represented by the yield to maturity. Therefore, a proper risk measure is represented by the modified duration of the portfolio. Thus, in a Markowitz-oriented approach (Markowitz, 1952), we can assume that investors maximize their portfolio future wealth for a fixed portfolio modified duration. Therefore, considering a market in which no short selling is allowed, we can distinguish between the two following reward-risk approaches.

\subsection{Portfolio selection model}

In the first reward-risk approach, we consider $n$ bonds and define the vector of their returns to maturity $\mathbf{r}=\left[r_{1}, \ldots, r_{n}\right]^{\top}$, their modified duration $\mathbf{D}=\left[D_{1}, \ldots, D_{n}\right]^{\top}$ and the wealth invested in each bond $\mathbf{v}=\left[v_{1}, \ldots, v_{n}\right]^{\top}$ Then, we have that $v_{i}=y_{i} \cdot P_{i}$, where $y_{i}$ is the number of $i$-th bonds we buy and $P_{i}$ is the price of each of them. Moreover, we assume we can approximate the portfolio modified duration by using the formula:

$$
D_{(p)}=\frac{\mathbf{v}^{\top} \mathbf{D}}{\sum_{i=1}^{n} v_{i}} .
$$

In a reward-risk framework, investors want to maximize the expected future wealth approximated by $\sum_{i=1}^{n} v_{i}\left(1+r_{i}\right)$ and to control the portfolio modified duration $D_{(p)}$.

Then, investors will choose a solution to the following optimization problem:

$$
\begin{gathered}
\max _{y_{i}} \sum_{i=1}^{n} v_{i}\left(1+r_{i}\right), \\
\text { s.t. } \sum_{i=1}^{n} y_{i} P_{i}=W, \\
\frac{\mathbf{v}^{\top} \mathbf{D}}{W}=d \\
\frac{y_{i} \cdot P_{i}}{W} \leq q,
\end{gathered}
$$

$$
\begin{aligned}
& v_{i}=y_{i} \cdot P_{i}, \\
& y_{i} \geq 0 ; i=1, \ldots, n .
\end{aligned}
$$

for a maximum concentration threshold $q$, a fixed level of modified duration $d$ and a given available wealth $W$. It is clear that such optimization does not require historical observations of bond returns to estimate reward and risk measures.

\subsection{Portfolio problem to manage market risk}

The second risk-reward approach is designed to control market risk. In particular, considering a benchmark with return $r_{b}$ and $n$ assets with vector of returns $\mathbf{r}=\left[r_{1}, \ldots, r_{n}\right]^{\top}$, the classical portfolio selection problem in the reward-risk framework consists of minimizing a given risk functional $\rho$ provided that the reward functional $R$ of the portfolio returns greater than or equal to a threshold level $m$. Among the efficient choices obtained by varying the value of the constraint $m$, there is a portfolio (commonly called a market portfolio) that provides the maximum excess reward per unit of risk. Thus, assuming that the reward and risk are both positive, the market portfolio is obtained as the solution to the following optimization problem:

$$
\max _{x_{i}} \frac{R\left(\mathbf{x}^{\top} \mathbf{r}-r_{b}\right)}{\rho\left(\mathbf{x}^{\top} \mathbf{r}\right)},
$$

$$
\begin{aligned}
& \text { s.t. } R\left(\mathbf{x}^{\top} \mathbf{r}\right) \geq m, \\
& \sum_{i=1}^{n} x_{i}=1, \\
& x_{i} \geq 0 ; i=1, \ldots, n,
\end{aligned}
$$

where the return $\mathbf{x}^{\top} \mathbf{r}=\sum_{i=1}^{n} x_{i} r_{i}$ is the return of a portfolio with composition $\mathbf{x}=\left[x_{1}, \ldots, x_{n}\right]^{\top}$, and the no-short-selling assumption is represented by $x_{i} \geq 0, \forall i$. Starting from the original Markowitz's analysis, Sharpe suggested that investors should maximize the so-called Sharpe ratio (Sharpe, 1994) which adopts the expected value of the return as the reward functional and the standard deviation as the risk functional:

$$
S R(x)=\frac{E\left(\mathbf{x}^{\top} \mathbf{r}-r_{b}\right)}{S T D\left(\mathbf{x}^{\top} \mathbf{r}\right)} .
$$


In this case, the expected return and the standard deviation of the portfolio must be estimated on the historical observations.

\subsection{Portfolio selection problem}

Since the available historical series of BRICS bonds are not homogeneous, we consider Brazilian bond data from October 26, 2011 to April 27, 2015 (915 observations) and for Russia, India, China and South Africa from May 11, 2005 to April 27, 2015 (2600 observations). The number of observations corresponds to the number of trading days. The adjusted price series of each bond is obtained from Thomson Reuters DataStream. After a first cleaning of the data, we apply a Principal Component Analysis (PCA) to determine those few principal components that account for most of the portfolio's variability. Therefore, we approximate the returns by regressing them on those few principal components in order to improve the robustness of the approximations of the performance measures in the portfolio selection model (see, among others, Biglova et al., 2009). The optimal portfolio selection is applied to the preselected approximated returns. We address the bond portfolio applying the two phases described in the previous section. In each phase, we manage a specific risk source. In the first phase, we control the price risk with the methodology proposed in section 2.1; in the second phase, we consider the market risk with the approach defined in section 2.2. Specifically, we proceed as follows.

1. In the first phase, we solve model (2) for a given set of fixed modified durations $d$ and we compute the ex-post wealth obtained. In particular, for each value of $d$, every 20 days we compute the optimal portfolio and using a rolling horizon approach, we describe the wealth path followed by a constant duration fund. Clearly, each fund allocation changes periodically to maintain the constant duration. Thus, the result of this first phase is a set of funds and their ex-post wealth.

2. In the second phase, we use the funds obtained in the first phase as assets and consequently their ex-post wealth as historical series. Then, solving model (3) using the Sharpe ratio (4) as the performance measure, we reduce the market risk and we create an optimal portfolio of funds and its ex-post wealth. The benchmark return $r_{b}$ is always set to zero for a more consistent final comparison between all the countries.

Model (2) is a fully linear programming problem and, therefore, each optimization can be performed in a very efficient way within seconds. Model (3) is more complex because it requires the optimization of the performance measure which is a ratio between two functionals. Nevertheless, we can reformulate it as a quadratic programming problem according to the classification in Stoyanov et al. (2007) and each optimization can be performed with common solvers. Thanks to this reformulation and considering the dimension induced by our setting, the computation time is less than one minute. In the next section, the described two-step procedure for portfolio selection is applied to the five BRICS countries separately. The results are obtained using MATLAB R2013b with an Intel R CoreTM i7-4510U CPU $2.60 \mathrm{GHz}$ with 8.00 GB RAM running Windows 10.

\section{EMPIRICAL ANALYSIS}

In this section, we compute the ex-post wealth obtained in each BRICS country by applying the twostep optimization methodology described above.

\subsection{First phase results}

For each BRICS, considering a fixed modified duration and an initial wealth of 100,000 units of the each state's currency, every 20 days we recalibrate the portfolio to optimize model 2. Owing to a lack of data, we consider a different grid of 20 durations $d$ for each country. At each recalibration, the wealth of the portfolio is computed according to the returns observed between the current rebalancing time and next one. The result of this process is a set of 20 optimal portfolios, one for each fixed duration, and we observe the evolution of the ex-post wealth of each of them over the considered time horizon. Figure 1 shows the evolution of the wealth obtained with the optimal portfolios which include both sovereign and corporate Brazilian bonds. For the Brazilian case, the considered 20 durations go from 0.5 to 4.7 years. Observing Figure 1, we can conclude 


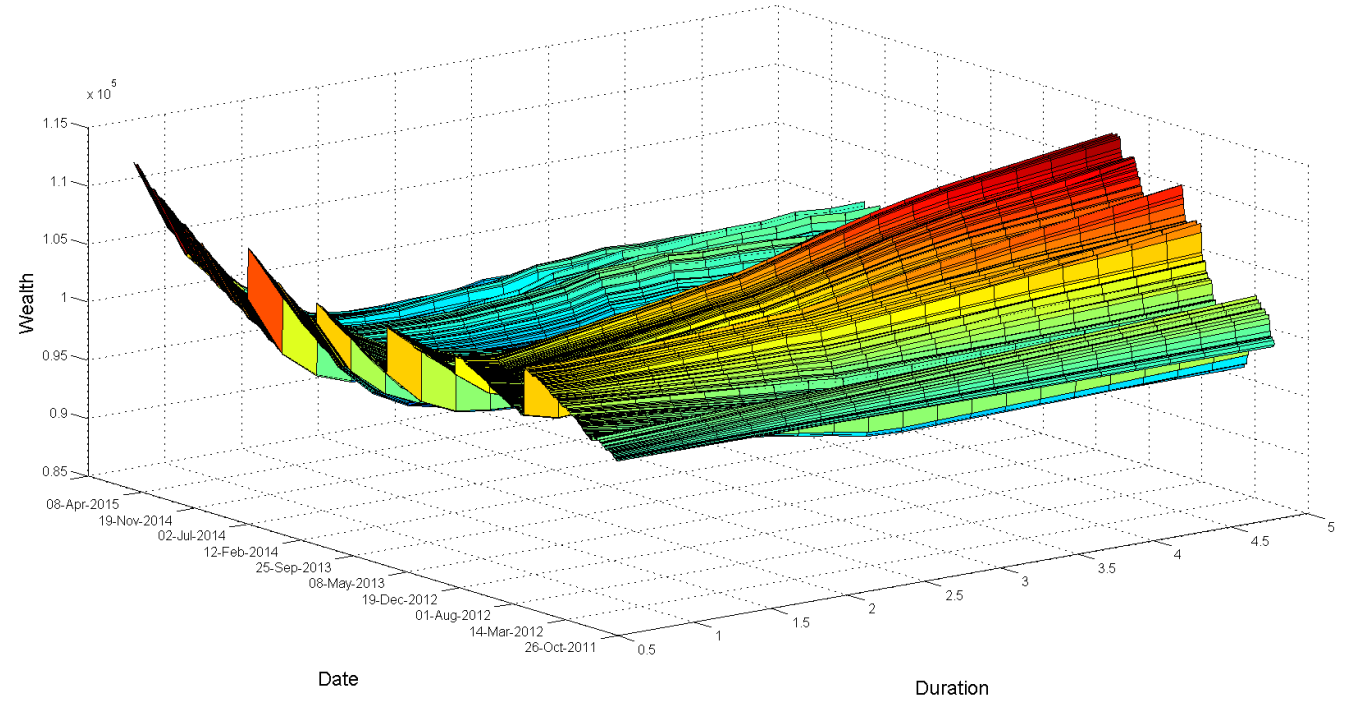

Figure 1. Ex-post wealth on Brazilian bond portfolios after first phase (October 2011-April 2015)

that all portfolios have a positive return over the whole period. Specifically, for short-term durations, the portfolios suffer periodic drawdowns but achieve a final return of almost $15 \%$, while longer duration portfolios display a remarkable return until mid-2013 and then a sudden loss which nullifies the previous gains.

Figure 2 shows the evolution of the wealth of the optimal portfolios composed by corporate and sovereign Russian bonds (from 2011 to 2015). For the Russian case, the considered 20 durations go from 2 to 12.4 years. The trend of these portfolios is almost flat until the Russian gas crisis. After that, we observe a very volatile period followed by extremely positive returns which allow the portfolio to reach seven times the initial wealth. This effect is gradually reduced for increasing duration.

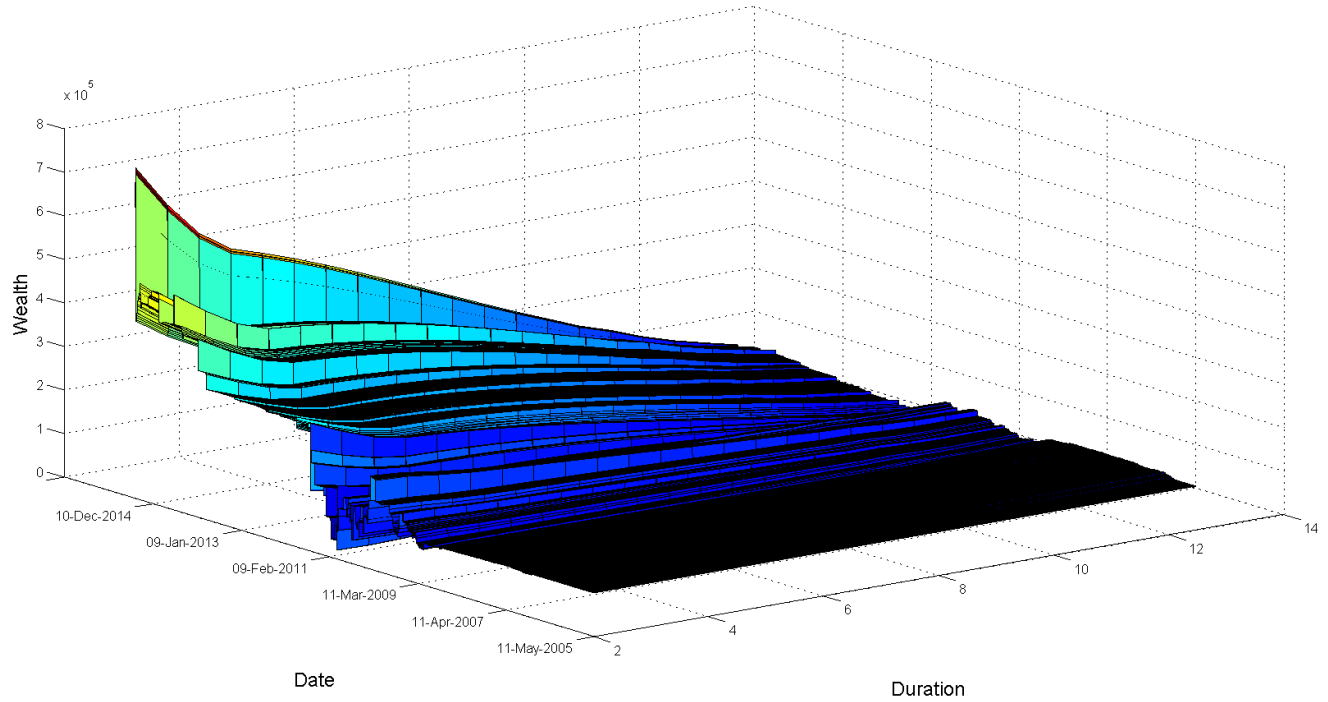

Figure 2. Ex-post wealth on Russian bond portfolios after first phase (May 2011-April 2015) 


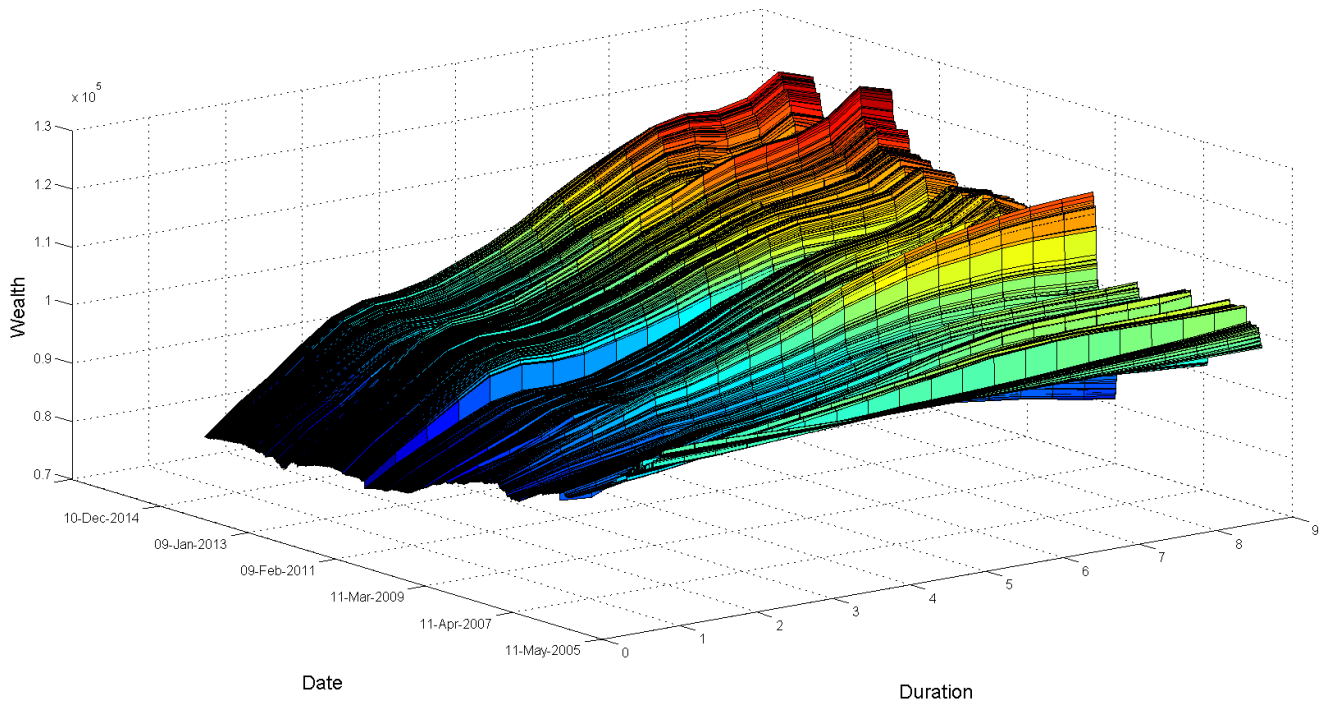

Figure 3. Ex-post wealth on Indian bond portfolios after first phase (May 2011-April 2015)

The evolution of optimal portfolios obtained with sovereign and corporate Indian bonds is shown in Figure 3. For the Indian case, the considered 20 durations go from 0.8 to 8.6 years. On the one hand, portfolios with short-term duration slowly decrease over the horizon considered. On the other hand, portfolios with longer duration are more volatile but are also able to exploit market movements and increase the initial wealth. The Indian case is the only one for which the relation between shortand long-term duration portfolios follows its natu- ral trend, i.e. the long-term duration portfolios are more volatile and with higher mean returns.

Figure 4 shows the evolution of the wealth of the optimal portfolios composed by corporate and sovereign Chinese bonds. For the Chinese case, the considered 20 durations go from 0.5 to 3.8 years. The chart shows that, from 2005 to 2010 , it is more profitable to invest in medium-term bonds as there is a constant increase in wealth. After 2010, all portfolios appear to be flat and we

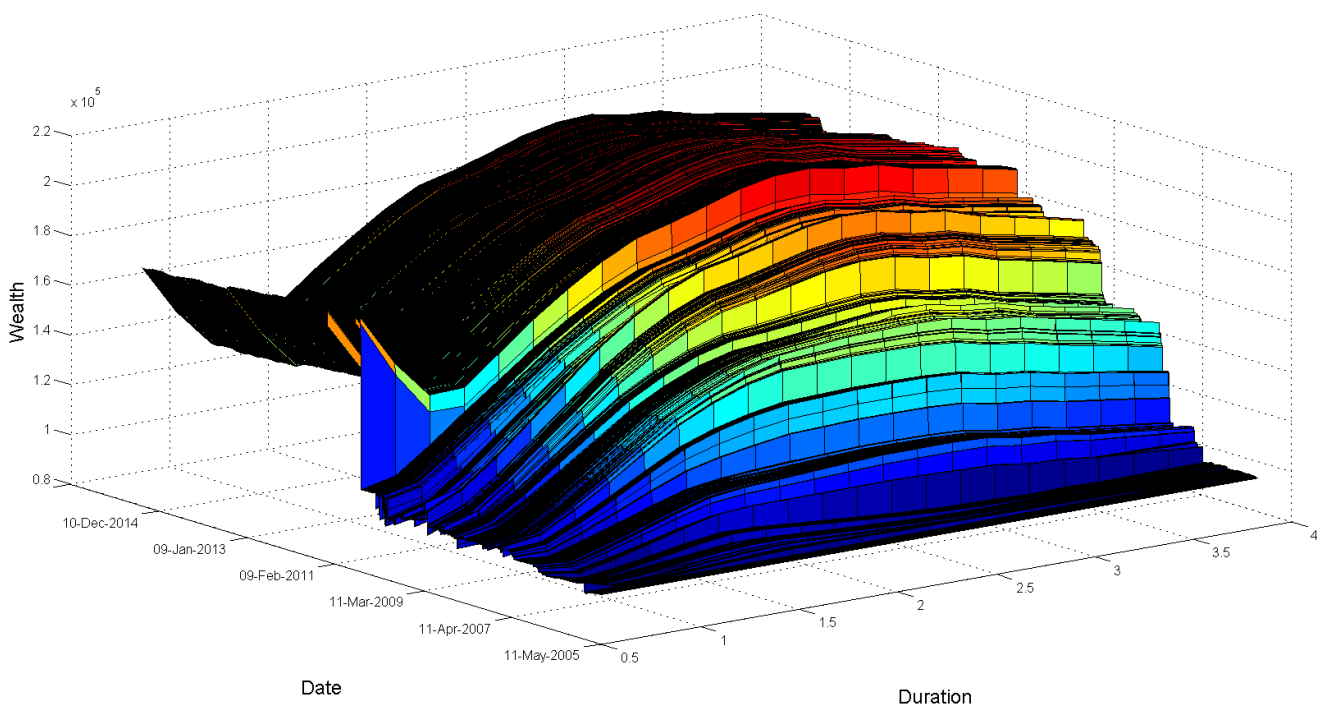

Figure 4. Ex-post wealth on Chinese bond portfolios after first phase (May 2011-April 2015) 


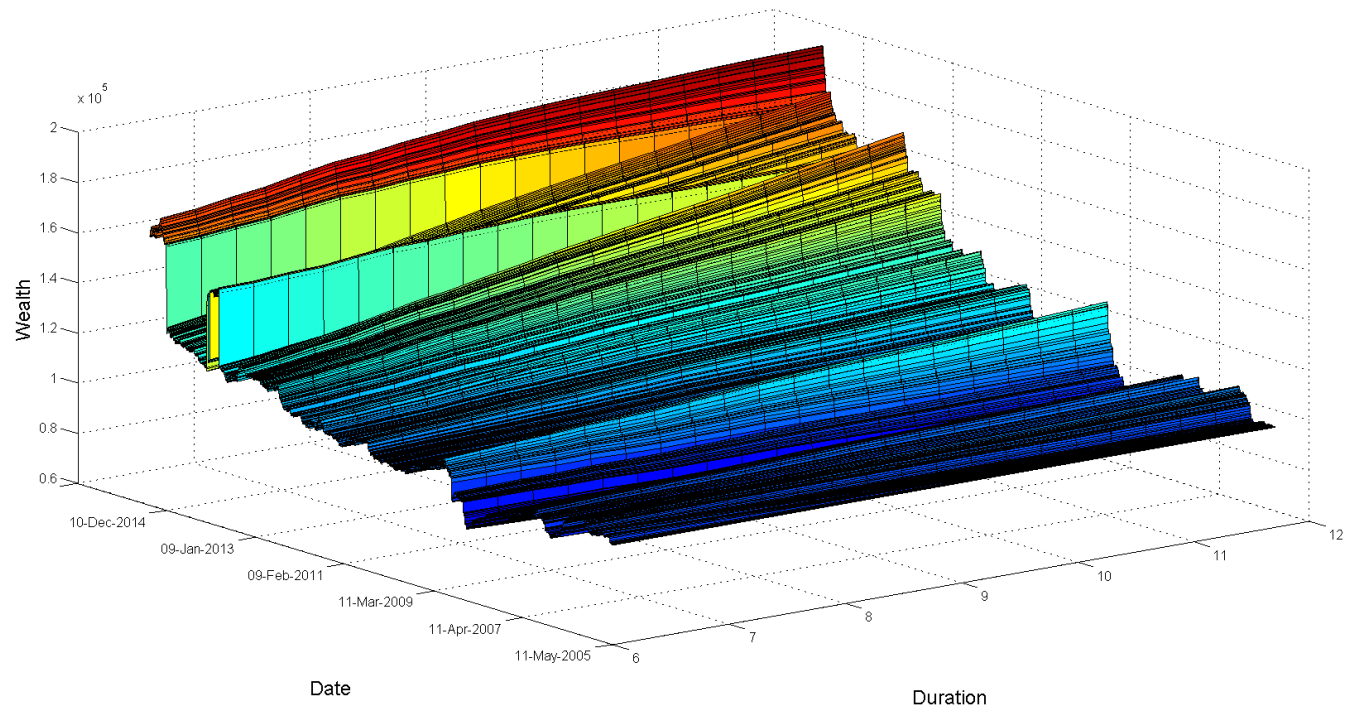

Figure 5. Ex-post wealth on South African bond portfolios after first phase (May 2011-April 2015)

observe a huge increase in the short-term duration portfolios reasonably due to the change in the credit risk of China sovereign debt followed by an increase of the ratio between the public debt and the GDP.

Finally, in Figure 5, we show the evolution of the wealth resulting from the optimal portfolio composed by sovereign and corporate bonds of South Africa. In this case, the considered 20 durations go from 0.5 to 4.7 years. The returns of the portfolios are not significantly differentiated accord- ing to the duration. Only in the last few years do the returns reflect the duration, i.e. long durations correspond to higher returns. In summary, the final wealth of the portfolios is always higher than the initial wealth growing smoothly except for some shocks on the shortest durations.

\subsection{Second phase results}

In the second phase, for each country, the 20 optimal funds created in the first phase are used to create a unique portfolio that solves model

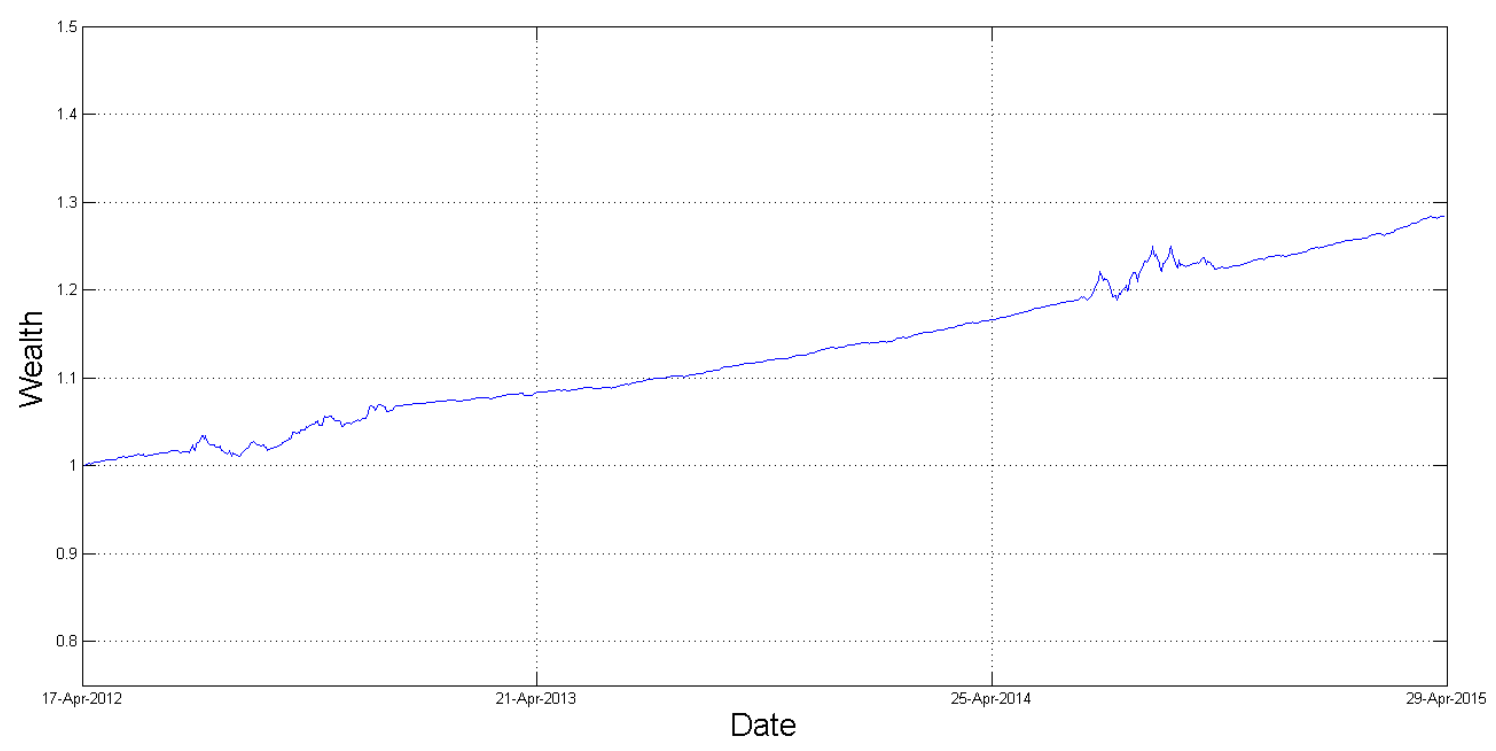

Figure 6. Ex-post wealth on Brazilian bonds after second phase 


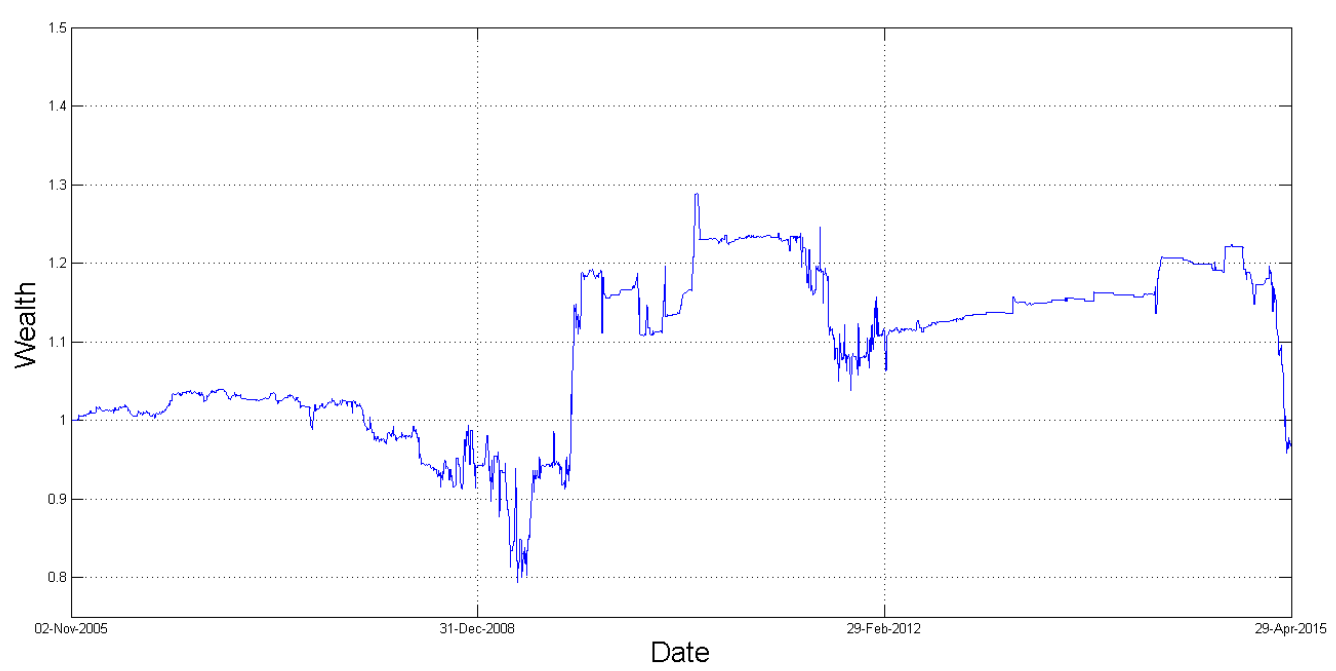

Figure 7. Ex-post wealth on Russian bonds after second phase

(3). Since we adopt the Sharpe ratio (4) to measure the performance, we need historical series to evaluate and reduce the market risk. Thus, at each recalibration, we consider the previous 125 trading days of the funds to estimate the expected excess return and the standard deviation of the portfolio. Moreover, the recalibration frequency is increased from 20 trading days of the first phase to 5 trading days, i.e. we adopt a weekly rebalancing which is more widely used in the literature to control the market risk, e.g. in stock strategies. Figure 6 shows the ex-post wealth of the optimal portfolio of funds for the Brazilian bonds markets. The growth of the portfolio wealth is almost always constant.
We observe two very volatile periods at the end of 2012 and at the end of 2014 due to the economic crisis of the country which is reflected on a greater uncertainty in the bond markets. Considering the whole period, the portfolio achieved a final wealth which is more than 1.25 times the initial wealth.

Figure 7 shows the results for the Russian bond market. In the first period until July 2008, we observe a very conservative strategy which produce a return almost equal to zero. Afterwards, the wealth path highlights a very volatile period that occurs during the Russian gas crisis and results in a huge loss. The same event is indeed visible in

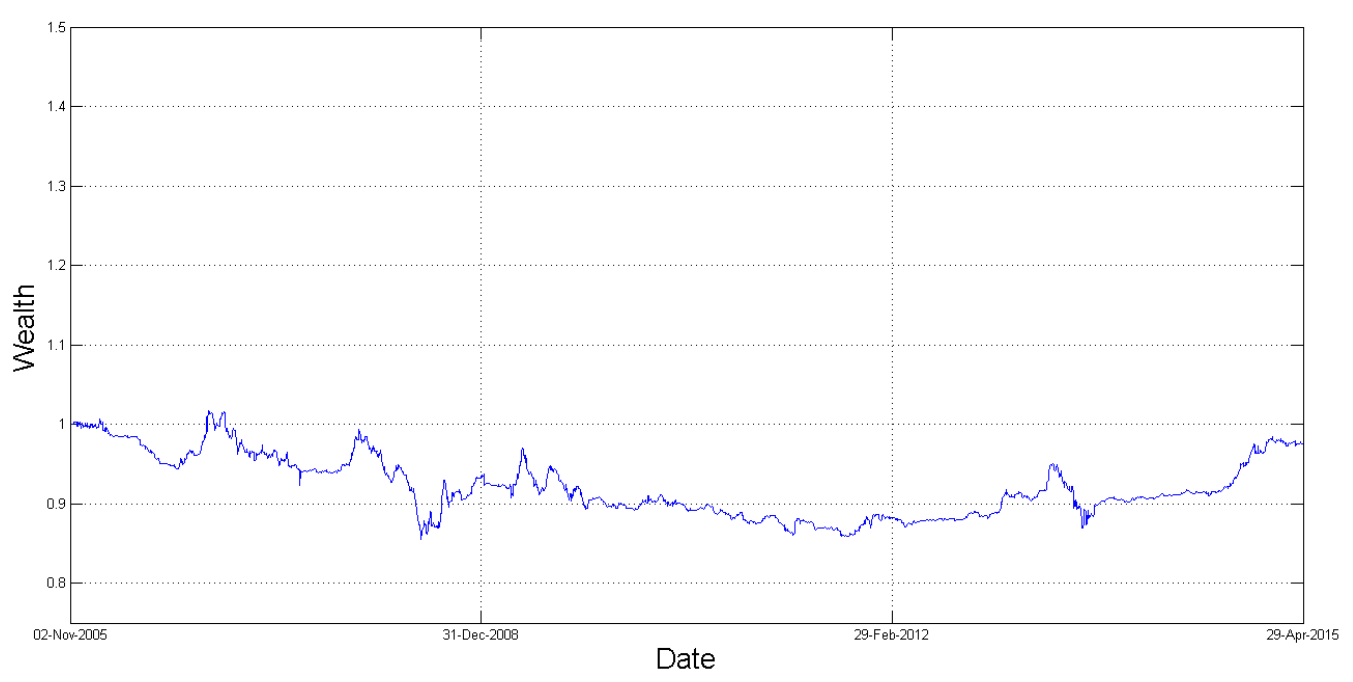

Figure 8. Ex-post wealth on Indian bonds after second phase 


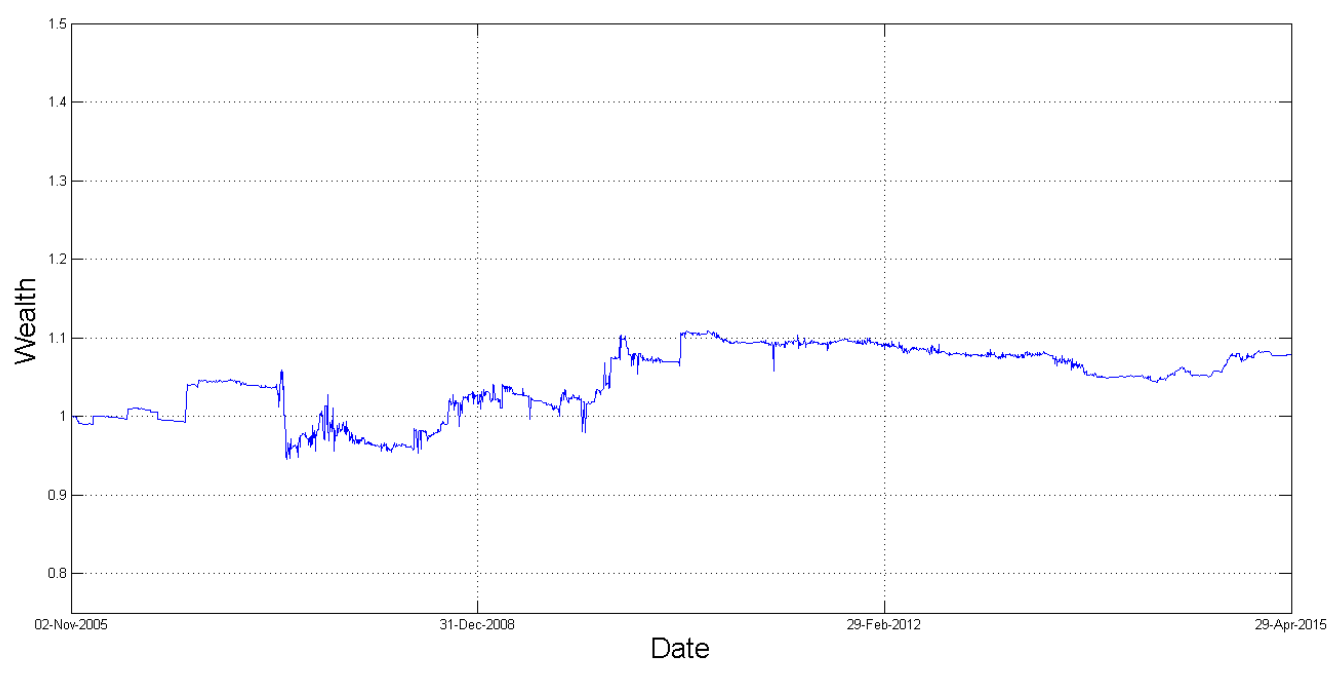

Figure 9. Ex-post wealth on Chinese bonds after second phase

Figure 2 where all funds suffer market turmoil, no matter the duration. After the beginning of 2011, the portfolio quickly recovers exploiting the performance of the shorter duration funds and during this period reaches 1.2 times the initial wealth. During the next few years, the 2010 crisis induces another drawdown after which the portfolio recovered slightly. Only for the very last observations do we observe a quickly negative shock that brings the portfolio value back to the initial wealth.

As shown in Figure 8, the portfolio composed of Indian bonds is often characterized by negative returns. This is induced by the poor performance of the shorter duration funds and the volatile behavior of the longer duration funds as highlighted in Figure 3. Therefore, we observe less volatility than in the previous countries in the whole ex-post wealth since it reached a maximum loss of $23 \%$ and a maximum gain of $3 \%$ with respect to the initial wealth. The peak of the loss is reached during August 2008, i.e. during the financial crisis. After a quick recovery, the trend reverses again to negative until early 2012. In the following period, the portfolio value increases again until a new collapse in August 2013 when a monetary crisis occurred, especially with respect to the US dollar. From 2013, we see a new recovery but the portfolio does not reach the initial wealth.

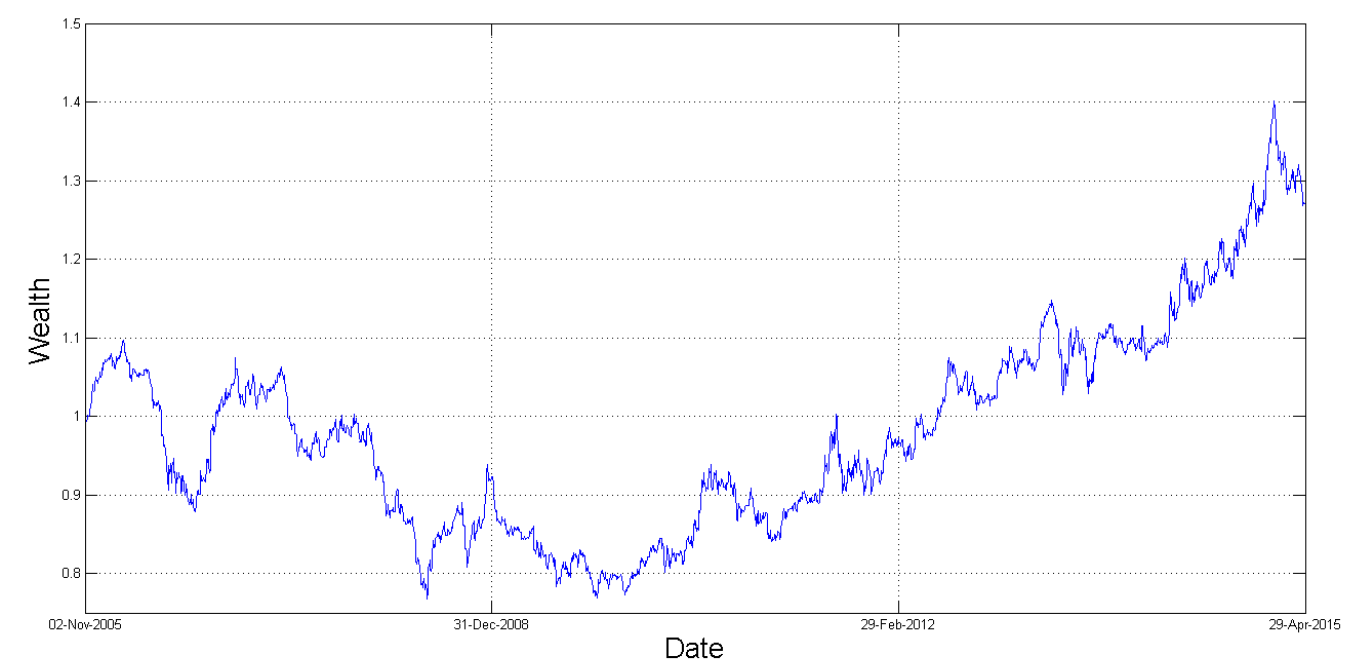

Figure 10. Ex-post wealth on South African bonds 
Table 1. Dominance relations between the strategies in different countries

\begin{tabular}{l|c|c|c|c|c}
\hline & Brazil & China & India & Russia & South Africa \\
\hline Brazil & n.c. & SSD & SSD & SSD & SSD \\
\hdashline China & - & n.c. & - & - & - \\
\hdashline India & - & TSD & n.c. & - & SSD \\
\hline Russia & - & TSD & - & n.c. & TSD \\
\hline South Africa & - & - & - & - & n.c. \\
\hline
\end{tabular}

The Chinese portfolio is characterized by extremely volatile periods. Indeed, as shown in Figure 9, there is a constant increasing trend of the returns interspersed with remarkable jumps. During the global financial crisis, the returns remain positive on average, even if the volatility contiues to be relatively high. The positive trend ceases during 2010 and then the portfolio slowly decreases until a recovery starting in the beginning of 2015.

Finally, in Figure 10, we show the trend of the wealth of the portfolio that invests in South Africa bond markets. The portfolio follows a cyclical path until the end of 2009 with periods of positive returns alternating with periods of negative trend. From 2010 the average trend stabilizes and assumes a positive value. The only remarkable exception occurs during 2013 and 2014 when South Africa experienced some internal economic problems. After this, we again observe positive returns that allow the portfolio to reach almost 1.4 times the initial wealth.

\subsection{Stochastic dominance relation test}

In this section, we investigate more analytically the behavior of the five portfolios according to the stochastic dominance theory. Stochastic dominance relations allow the whole distribution of the portfolio returns to be compared, not restricting the analysis to the moments of the considered distributions. The definition of first order stochastic dominance (FSD) is as follows: a random variable A first order stochastically dominates a random variable $B$ if the cumulative probability distribution function of $\mathrm{A}$ is below that of $B$. An equivalent definition that regards the utility theory is the following: A first order stochastically dominates B if and only if the expected utility of $A$ is greater than or equal to the expected utility of
B for all utility (non-decreasing) functions; hence, every non-satiated investor prefers A to B or is indifferent between them. Similarly, the definition of second order stochastic dominance (SSD) is as follows: a random variable A second order stochastically dominates a random variable $B$ if the integrated cumulative probability distribution function of A is below that of B. Alternatively, A second order stochastically dominates $B$ if and only if the expected utility of $A$ is greater than or equal to the expected utility of $B$ for all concave utility functions; hence, every non-satiated and risk-averse investor prefers $\mathrm{A}$ to $\mathrm{B}$ or is indifferent between them. Finally, the definition of third order stochastic dominance (TSD) is as follows: a random variable $A$ third order stochastically dominates a random variable $B$ if the twice integrated cumulative probability distribution function of $\mathrm{A}$ is below that of $\mathrm{B}$. Then $\mathrm{A}$ is preferred to be for every non-satiated, risk-averse and skewness-lover investor.

For an overview of the literature, we suggest the recent works (Davidson \& Duclos, 2000; Müller \& Stoyan, 2002; Kopa \& Post, 2009) and references therein, and examples of applications can be found in Kopa et al. (2016) and Cirelli et al. (2017). In particular, we analyze the presence of FSD, SSD and TSD. The results are reported in Table 1. We observe that there is no FSD relation. The Brazilian portfolio dominates in the SSD sense, while the Indian portfolio dominates the Chinese portfolio in the TSD sense and the South African portfolio in the SSD sense. The Russian portfolio dominates both the Chinese and the South African portfolio. Therefore, $\mathrm{u}$ the stochastic dominance relation test, we verify that any non-satiable and riskaverse investor should prefer the Brazilian portfolio, but the Indian and Russian portfolios are still preferable in the same sense to Chinese and South African portfolios. 


\section{CONCLUSION}

The purpose of this paper was to analyze a two-step optimization in the bond markets of BRICS countries. The BRICS markets offer huge opportunities to create diversified portfolios. The variety of the types of issuers, of maturities and of ratings is not as wide as in developed countries, but still sufficient to attract investors. Therefore, for each considered country, our approach takes advantage of such diversification to create the first sets of portfolios with fixed duration and then to compose a portfolio of funds which shows remarkable returns. The crisis periods also affected the BRICS market, even if not as dramatically as in developed countries. Moreover, despite the common thinking that the BRICS markets behave approximately equally, our analysis highlights great differences. In the first step, we note that in the Brazilian market, the long duration funds offer interested returns only until 2012 while short duration funds produce medium and volatile returns. All Russian funds highlight a huge turmoil in 2010 and then only the short duration funds recover and produce very positive returns. The Indian funds with long duration have a positive trend, while the short duration funds are not able to conserve their value over the considered horizon. The Chinese funds show a positive return for long durations but also carry very high volatility. The South African funds are also very volatile, and do not show major differences between short and long durations.

As far as the second step is concerned, the Brazilian bond portfolio offers a stable return. The Russian portfolio suffers during the crisis of 2008 but then recovers rapidly. The Indian portfolio loses a large part of its value during the 2007 crisis and despite a partial recovery is not able to return the initial wealth. The Chinese bond portfolio observes some flash draw-downs during the crisis and immediately recovers. The South African portfolio also suffers because of the crisis, but from 2010 constantly increases reaching almost 1.4 times the initial wealth.

The stochastic dominance relation tests confirm the observations proposed previously and indicate that, in particular, not only the Brazilian portfolio, but also the Russian and the Indian portfolios, should be preferred to the Chinese and Indian portfolios by a large class of investors.

Further research should investigate a common portfolio instead of differentiated portfolios for each country, i.e. to invest jointly in all BRICS bond markets rather than individually in each of them. Moreover, it should be possible to investigate different types of immunization for the first phase and other performance measures for the second phase. Finally, the stochastic dominance relations could be implemented as additional constraints and not only as an ex-post test.

\section{ACKNOWLEDGEMENT}

This paper has been supported by the Italian funds ex-MURST 60\% 2017, Resp. Scie. Sergio Ortobelli Lozza. The research was also supported through the Czech Science Foundation (GACR) under project 17-199815 and through SP2017/32, and SGS research project of VSB-TU Ostrava.

\section{REFERENCES}

1. Balbàs, A., Ibàñez, A., López,

S. (2002). Dispersion measures as immunization risk measures. Journal of banking \& finance, 26(6), 1229-1244. Retrieved from https://e-archivo.uc3m.es/bitstream/handle/10016/6484/dispersion_balbas_JBF_2002_ps.pdf
2. Biglova, A., Ortobelli, S. L., Rachev, S., \& Fabozzi, F. (2009). Modeling, estimation, and optimization of equity portfolios with heavy-tailed distributions. In S. Satchell (Ed.), Optimizing optimization: The next generation of optimization applications and theory (pp. 117-141). Amsterdam: Academic Press.

3. Bertocchi, M., Giacometti, R., Zenios, S. A. (2005). Risk factor analysis and portfolio immunization in the corporate 
bond market. European Journal of Operational Research, 161(2), 348-363.

4. Bertocchi, M., Consigli, G., D’Ecclesia, R., Giacometti, R., Moriggia, V., Ortobelli, S. (2013). Euro bonds: Markets, infrastructure and trends. World Scientific Books.

5. Cassader, M., Ortobelli, S., Caviezel, V., Caglio, S. (2014). On the use of contingent claims in portfolio selection problems. International Journal of Economics and Statistics, 2, 220-229.

6. Cirelli, S., Vitali, S., Ortobelli Lozza, S., Moriggia, V. (2017). A conservative discontinuous target volatility strategy. Investment Management and Financial Innovations, 14(2-1), 176-190. http://dx.doi.org/10.21511/ imfi.14(2-1).2017.03

7. Davidson, R., Duclos, J. Y. (2000). Statistical inference for stochastic dominance and for the measurement of poverty and inequality. Econometrica, 68(6), 1435-1464.

8. Fisher, L., Weil, R. L. (1971). Coping with the risk of interestrate fluctuations: returns to bondholders from naive and optimal strategies. Journal of business, 44(4), 408-431. Retrieved from http://www.jstor.org/ stable/2352056?seq=1\#page_scan_ tab_contents

9. Fooladi, I. J., Roberts, G. S., Skinner, F. (1997) Duration for bonds with default risk. Journal of Banking \& Finance, 21(1), 1-16.

10. IMF (2011). World economic outlook. Retrieved from http:// www.imf.org/external/pubs/ft/ weo/2011/01/weodata/index.aspx

11. Kopa, M., Post, T. (2009). A portfolio optimality test based on the first-order stochastic dominance criterion. Journal of Financial and Quantitative Analysis, 44(05), 1103-1124.

12. Kopa, M., Moriggia, V., Vitali, S. (2016). Individual optimal pension allocation under stochastic dominance constraints. Annals of Operations Research, 1-37.

13. Markowitz, H. (1952). Portfolio selection. The journal of finance, 7(1), 77-91. Retrieved from http://onlinelibrary.wiley.com/ doi/10.1111/j.1540-6261.1952. tb01525.x/full

14. Mathieson, D. J., Schinasi, G. J. (2001). International Capital Markets: Developments, Prospects, and Key Policy Issues (August 2001). International Monetary Fund.

15. Müller, A., Stoyan, D. (2002). Comparison methods for stochastic models and risks. Chichester: John Wiley\&Sons Ltd.

16. Munk, C. (2011). Fixed income modelling. Oxford University Press.

17. O’Neill, J. (2011). Building Better Global Economic BRICs. Goldman Sachs Asset Management View Point.

18. Ortobelli, S., Petronio, F. (2015). An analysis of fixed income BRICS markets. Proceedings of 10th International Scientific Conference Financial management of Firms and Financial Institutions, Ostrava.

19. Ortobelli, S., Vitali, S., Cassader, M., Tichỳ, T. (2016). Portfolio selection strategy for fixed income markets with immunization on average. Annals of Operations Research, 1-21.

20. Paroush, J., Prisman, E. Z. (1997). On the relative importance of duration constraints. Management
Science, 43(2), 198-205. Retrieved from https://pubsonline.informs.org/doi/abs/10.1287/ mnsc.43.2.198

21. Petronio, F., Tamborini, L., Lando, T., Ortobelli Lozza, S. (2014). Portfolio selection in the BRICs stocks markets using Markov processes. International Journal of Mathematical Models and Methods in Applied Sciences, 8, 311-318.

22. Redington, F. M. (1952). Review of the principles of life-office valuations. Journal of the Institute of Actuaries, 78(3), 286-340.

23. Sharpe, W. F. (1994). The Sharpe ratio. The journal of portfolio management, 21(1), 49-58,

24. Stoyanov, S. V., Rachev, S. T., Fabozzi, F. J. (2007). Optimal financial portfolios. Applied Mathematical Finance, 14(5), 401-436.

25. Thompson, J. (2010). Current and structural developments in the financial systems of OECD enhanced engagement countries. OECD Journal: Financial Market Trends, 2009(2), 209-263.

26. De la Torre, A., Schmukler, S. (2006). Emerging capital markets and globalization: the Latin American experience. World Bank Publications.

27. Vašiček, O. (1977). An equilibrium characterization of the term structure. Journal of Financial Economics, 5(2), 177-188.

28. Weil, R. L. (1973). Macaulay's duration: An appreciation. The Journal of Business, 46(4), 589-592.

29. Zenios, S. A. (1995). Asset/liability management under uncertainty for fixed-income securities. Annals of Operations Research, 59(1), 77-97. 